\title{
Uso de áreas verdes na expansão de conjuntos habitacionais no Subúrbio de Salvador, Bahia
}

\author{
Use of green areas for expansion of housing estates in the Suburb of Salvador, Bahia.
}

\author{
VIANA $^{1}$, C. J.; FALCÃO ${ }^{2}$, P. M.
}

cassioviana1992@gmail.com

\begin{abstract}
Resumo
É sabido que o avanço da urbanização vem provocando impactos no meio natural, principalmente nas áreas verdes inseridas na cidade, as quais não são valorizadas, apesar dos benefícios ofertados na questão paisagística e da saúde. Frente a esse entrave, o presente estudo tem como objetivo expor a quantidade de espaços verdes reduzidos para a construção de conjuntos habitacionais iniciados no final da década de 60, no Subúrbio Ferroviário de Salvador. Para isso, tornou-se necessário lançar mão da seguinte sequência metodológica, composta por quatro etapas: (i) pesquisa bibliográfica, acerca dos conceitos de áreas verdes, fotointerpretação e expansão habitacional no subúrbio; (ii) identificação dos conjuntos habitacionais e elaboração da planilha com informações dos empreendimentos; (iii) obtenção das fotografias aéreas, fotointerpretação, georreferenciamento e cálculo de áreas verdes; (iv) trabalhos de campo e elaboração de mapas temáticos acerca das áreas verdes remanescentes. Por fim, os resultados apontaram que houve um processo elevado de supressão de áreas verdes na região provocados pela implantação dos primeiros complexos habitacionais e uma atividade mais discreta em relação aos mais recentes.
\end{abstract}

Palavras-chave: Subúrbio Ferroviário; Áreas Verdes; Conjuntos Habitacionais..

\begin{abstract}
It is well known that the advance of urbanization has caused impacts on the natural environment, mainly in the green areas inserted in the city, which are not valued, despite the benefits offered in the landscape and health issue. Faced with this obstacle, this study aims to expose the amount of green spaces reduced for the construction of housing complexes started in the late 60's, in the Suburb Railroad of Salvador. For this, it was necessary to use the following methodological sequence, composed of four stages: (i) bibliographical research on the concepts of green areas, photointerpretation and suburban housing expansion; (ii) identification of the housing complexes and preparation of the spreadsheet with information on the projects; (iii) obtaining aerial photographs, photointerpretation, georeferencing and calculation of green areas; (iv) fieldwork and thematic mapping of remaining green areas. Finally, the results indicated that there was a high process of suppression of green areas in the region caused by the implantation of the first housing complexes and a more discreet activity in relation to the more recent ones.
\end{abstract}

Keywords: Suburb Rail; Green areas; Housing estates.

\section{INTRODUÇÃO}

A intensa urbanização vivenciada pelas médias e grandes cidades brasileiras vem provocando, de acordo com Porto-Gonçalves (2006), sérios rebatimentos negativos na paisagem natural, pois o elevado adensamento habitacional, aliado a uma ineficiente administração dos gestores do solo urbano, faz surgir problemas como o acúmulo de lixo e de esgoto de origem doméstica e industrial, altos índices de impermeabilização do solo, deterioração das águas superficiais e subterrâneas e destruição de espécies da fauna e da flora. 
Esse quadro escalar de degradação dos recursos naturais em prol do avanço do modelo urbano também foi legado a Salvador, capital do Estado da Bahia. (figura 01) Acerca dessa cidade, nos limitaremos a expor apenas a degradação de suas áreas verdes, as quais segundo Mascarenhas e Cunha (2007), seu processo de redução se intensificou a partir da década de 1950, com a implantação das avenidas de vale e a ocupação de áreas periféricas, incluindo localidades voltadas à habitação da população mais abastada do município.

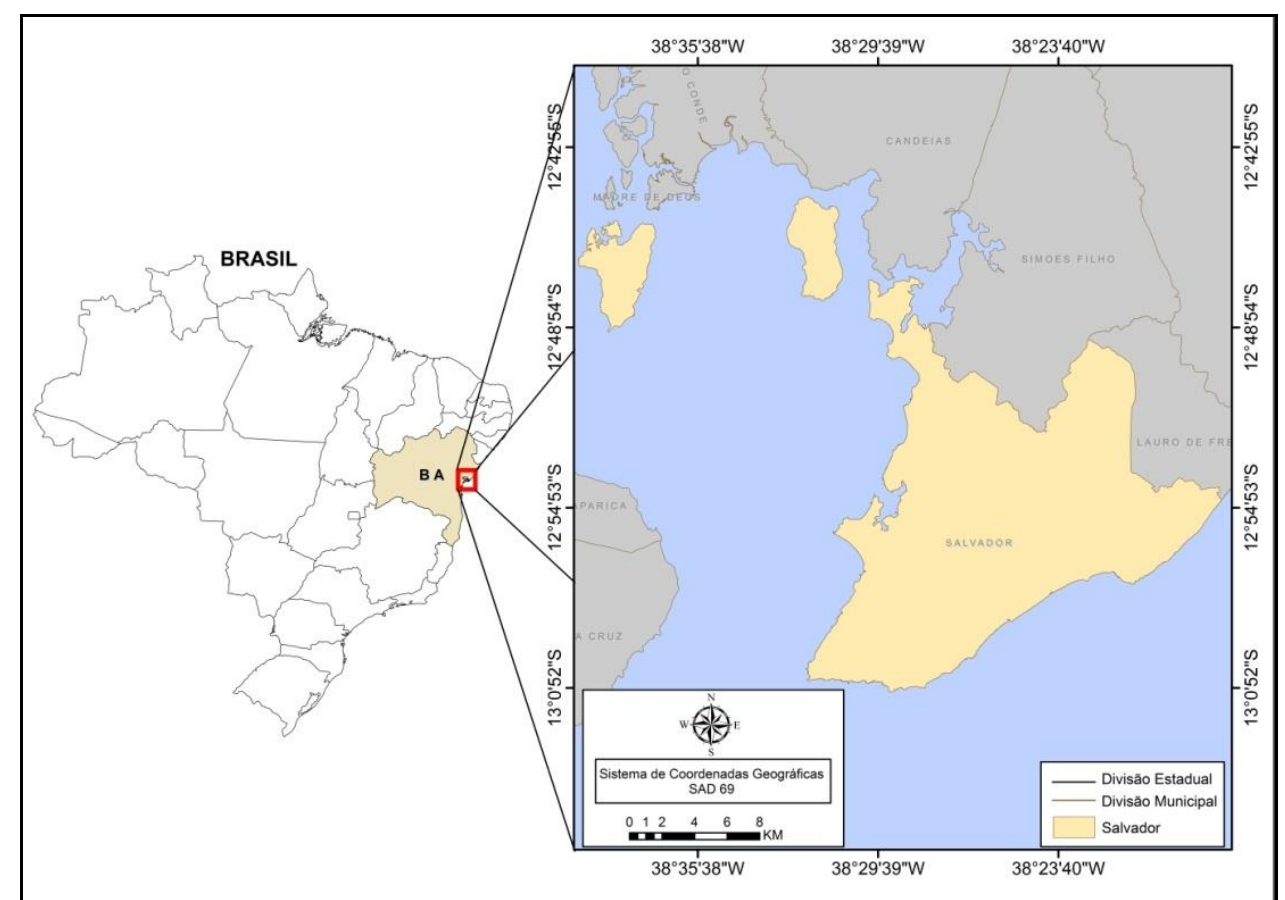

Figura 01: Subúrbio Ferroviário da cidade de Salvador. Fonte: Autores (2018)

Entretanto, é no final da década de 1960 que Salvador recebe um grande impulso na sua produção imobiliária planejada, através da URBIS (Urbanização e Habitação da Bahia), com a implantação de diversos conjuntos habitacionais, os quais, além de combater o déficit de moradia, visavam gerar novos vetores de expansão na cidade. Devido a essa postura, muitas áreas afastadas do centro urbanizado que predominava a vegetação nativa deram lugar a esses empreendimentos.

Atualmente, outro programa habitacional, o Programa Minha Casa Minha Vida (PMCMV), tem sido o responsável por desenvolver complexos habitacionais de forma semelhante aos produzidos pela extinta URBIS na capital baiana. E devido a isso, vem provocando o mesmo processo de remoção de áreas verdes na cidade, porém, essa acelerada redução destes espaços se revela como um sério problema para urbano, tendo em vista que a sua ausência interfere nas questões paisagísticas e até mesmo na saúde.

Logo, é no interior dessa relação entre redução de espaços verdes e implantação de habitações planejadas que colocamos em evidência o Subúrbio Ferroviário de Salvador, área que 
recebeu empreendimentos da URBIS e, atualmente, também vem recebendo os oriundos do PMCMV. Assim, o presente trabalho tem como objetivo analisar a expansão imobiliária através de conjuntos habitacionais no Subúrbio de Salvador e inferir um diagnóstico acerca do processo de supressão de áreas verdes atrelada à implantação desses sistemas planejados.

De fronte a isso, o presente trabalho se justificou pela importância em se mapear os conjuntos habitacionais construídos no Subúrbio Ferroviário de Salvador e compreender a quantidade de áreas verdes que foram suprimidas para a implantação destes. Além disso, contribui para o aprofundamento nos estudos de dois campos, a saber: os estudos ambientais das áreas verdes urbanas; e análises da urbanização do Subúrbio Ferroviário.

\section{METODOLOGIA}

Para a realização desse estudo foram estabelecidas quatro etapas: (I) pesquisa bibliográfica; (II) regionalização e construção de planilha com informações dos conjuntos habitacionais; (III) obtenção das fotografias aéreas, fotointerpretação, georreferenciamento e cálculo de áreas verdes; (IV) trabalhos de campo e elaboração de mapas temáticos.

A pesquisa bibliográfica serviu para construir a base teórico-metodológica deste trabalho. Dentre os assuntos pesquisados, destacamos aqui: a análise de fotografias aéreas; áreas verdes urbanas, com enfoque na parte conceitual; e a expansão habitacional planejada no Subúrbio Ferroviário de Salvador.

A segunda etapa consistiu na delimitação da área de estudo através da regionalização elaborada por Santos et al. (2010) junto com a CONDER (Companhia de Desenvolvimento Urbano da Bahia) para o Subúrbio Ferroviário de Salvador. Após isso, foi construída uma planilha no software Microsoft Excel 2012 ®, com os seguintes tópicos: nome do conjunto, início e entrega da obra, área total $\left(\mathrm{m}^{2}\right)$, número de unidades, endereço, tipologia das habitações (casa, edifício, sobrado). O preenchimento se deu com base em visitas a URBIS, órgãos envolvidos com a produção habitacional e endereços eletrônicos de construtoras.

Fizeram parte da terceira etapa a obtenção e análise das fotografias aéreas, georreferenciamento e cálculo das áreas verdes. Para este estudo, adotou-se o conceito formulado por Bargos e Matias (2011) para analisar as áreas verdes urbanas, as quais em suas palavras devem ser compreendidas como um

“[...] espaço livre urbano composta por vegetação arbórea e arbustiva (inclusive pelas árvores das vias públicas, desde que estas atinjam um raio de influência que as capacite a exercer as funções de uma área verde), com solo livre de edificações ou coberturas impermeabilizantes (em pelo menos $70 \%$ da área), de acesso público ou não, e que exerçam minimamente as funções ecológicas (aumento do conforto térmico, controle da poluição do ar e acústica, interceptação das águas das chuvas, e abrigo à fauna), estéticas (valorização 
visual e ornamental do ambiente e diversificação da paisagem construída) e de lazer (recreação)" (BARGOS; MATIAS, 2011, p.185).

As análises sobre interferências nas áreas verdes ocasionadas pela construção dos conjuntos, fez-se uso das fotografias aéreas verticais, disponíveis na plataforma online Geopolis Visualizador da CONDER e de satélites disponíveis no Google Earth. A análise dessas fotografias se deu sem o auxílio de estereoscopia, visando atender dois objetivos: delimitação da área ocupada pelo conjunto; e identificação das áreas verdes remanescentes e desmatadas.

Feito o delineamento de polígonos nas áreas verdes remanescentes e delimitada a área ocupada pelos empreendimentos, as fotografias foram georreferenciadas no software de SIG (Sistema de Informação Geográfica) ArcGIS 10.2.2 através da técnica de pontos de controle a partir de imagens de satélite do software Google Earth. Finalizado esse processo, empreendeu-se os cálculos dos polígonos contendo as áreas verdes e a área ocupada por cada conjunto no já referido software de SIG.

Acerca destes cálculos, é importante dizer que a delimitação das áreas ocupadas pelos conjuntos foi realizada por meio de fotografias realizadas nos projetos dos empreendimentos na sede dos órgãos públicos e sites de construtoras. Assim, estes cálculos podem apresentar resultados inferiores ou superiores aos reais. No entanto, salientamos que essa margem não excedeu, em nenhum caso $260 \mathrm{~m}^{2}$. Devido a isso, quando apresentamos as informações referentes às áreas verdes desmatadas ou remanescentes, sempre nos referimos a um valor aproximado.

Por fim, o último passo dessa seqüência metodológica corresponde às atividades de campo e produção de mapas temáticos. Os trabalhos de campo foram empregados com dois objetivos, a saber: verificar questões relacionadas com a fotointerpretação, a exemplo da identificação de feições geomorfológicas; e observar a evolução das ocupações informais sobre as áreas verdes remanescentes.

Feito isso, deu-se seguimento com a produção de mapas temáticos no programa ArcGIS 10.2.2, baseando-se nos modelos empregados nos trabalhos de Copque et al. (2011) e Mascarenhas e Cunha (2007), demonstrando o processo de redução das áreas verdes ocasionado pela construção do conjunto, a vegetação remanescente e a delimitação da área ocupada do empreendimento.

\section{RESULTADOS E DISCUSSÃO}

\section{1 Área de estudo}

A região do Subúrbio Ferroviário (figura 02) é conhecida atualmente pelos órgãos planejadores do espaço urbano de Salvador como Subúrbio/Ilhas, em decorrência da delimitação de bairros apresentada por Santos et al. (2010). Assim, o Subúrbio hoje é compreendido pela presença 
de quinze bairros: São Tomé, Paripe, Fazenda Coutos, Coutos, Nova Constituinte, Periperi, Praia Grande, Alto da Terezinha, Itacaranha, Plataforma, Rio Sena, São João do Cabrito; e pelas ilhas de Maré, dos Frades e Bom Jesus (INFORMS-CONDER, 2016).

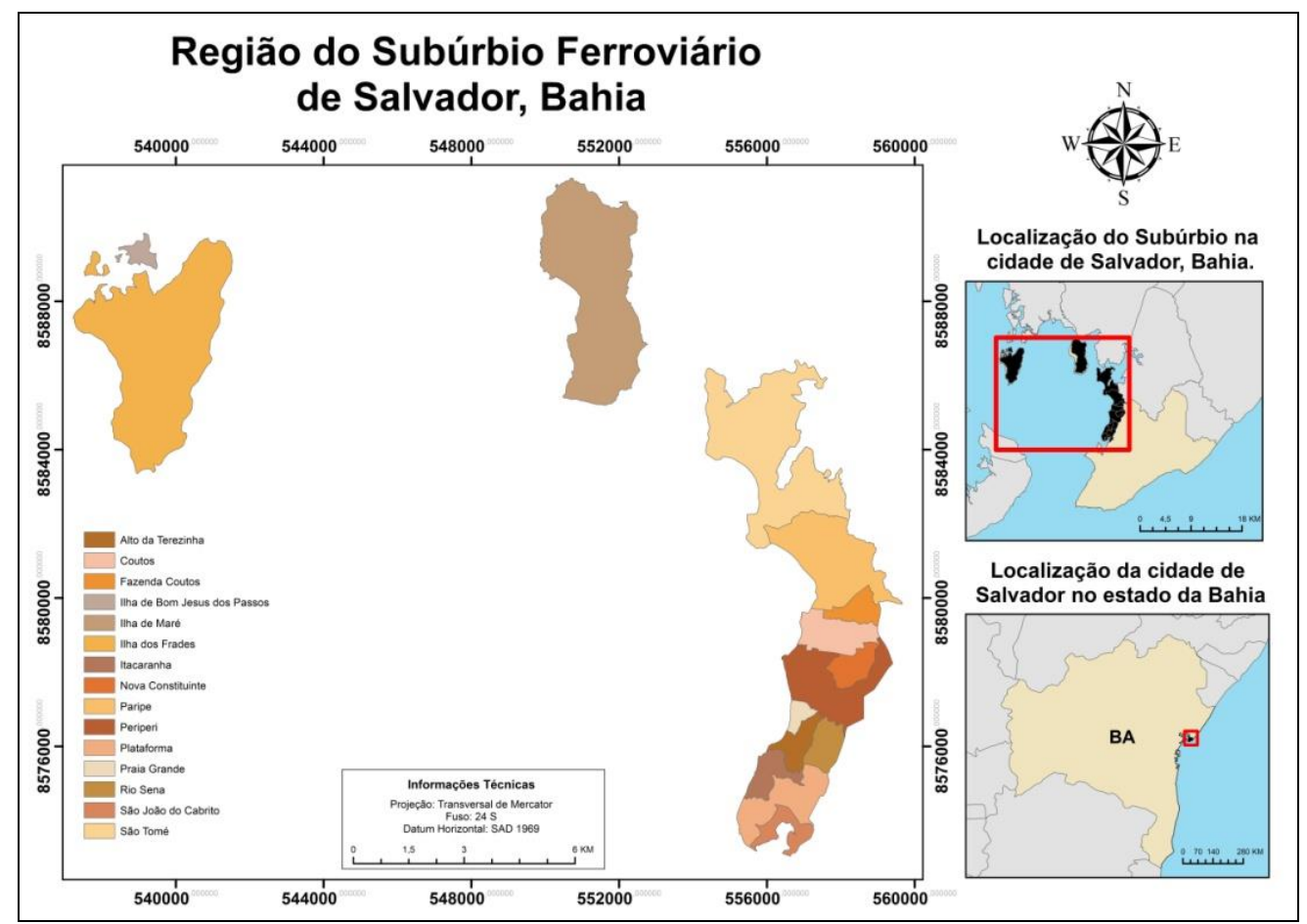

Figura 02: Subúrbio Ferroviário da cidade de Salvador. Fonte: Autores (2018)

Localizado na porção noroeste da capital baiana, o Subúrbio ocupa uma área de 52,86 km², sendo margeado durante toda a sua extensão pela Baía de Todos os Santos. Conforme o último censo realizado, ali viviam 283.415 pessoas, sendo $52,21 \%$ da população composta por indivíduos do sexo feminino e 47,79\% do sexo masculino (INFORMS-CONDER, 2016).

Em relação à tipologia da vegetação encontrada na região, nota-se a formação ombrófila densa (BRASIL, 1981), a qual se encontra bastante degradada por causa de sua remoção para a ocupação urbana. Acerca do solo da região, predominam, de acordo com a classificação da EMBRAPA (Empresa Brasileira de Pesquisa Agropecuário), os argissolos (SEI, 2001).

Ademais, as características geomorfológicas constituem um relevo erodido em lombas e colinas convexas muitas vezes, de forma tabular (BRASIL, 1981). No que tange à hidrografia, ali estão inseridas duas bacias hidrográficas responsáveis por drenar rios de caráter perene: a do rio Paraguari e parte da bacia do rio do Cobre, um dos sistemas fluviais mais salvaguardados da cidade de Salvador (SANTOS et al., 2010).

Ambos rios são regidos através do regime pluvial, em função do tipo climático da capital baiana, o qual segundo a classificação de THORNTHWAITE \& MATTHER é considerado úmido, 
megatérmico com evapotranspiração potencial >1140mm, apresentando pequena ou nenhuma deficiência hídrica ao longo do ano e precipitações mensais superiores a 100mm (SEI,1998).

3.2 Remoção de áreas verdes para a implantação de conjuntos habiticionais

\subsubsection{A Atuação da URBIS}

A construção de conjuntos habitacionais no estado da Bahia e no Subúrbio Ferroviário de Salvador está atrelada à fundação do BNH (Banco Nacional de Habitação) na década de 60, que promovia o financiamento de moradias via SFH (Sistema Financeiro Habitacional). A atividade desses dois agentes inaugurou uma nova fase da habitação planejada nessa região, a qual anteriormente esteve ligada apenas a vilas operarias, ocupações informais e loteamentos.

De acordo com Mendonça (1989) a construção de habitações em Salvador, neste período, esteve sobre o encargo de duas companhias: INOCOOP (Instituto de Orientação as Cooperativas Habitacionais) e da URBIS (Habitação e Urbanização da Bahia S.A). A ação desta primeira companhia de intermediação do SFH estava ligada ao mercado de habitações para famílias com rendimentos de 5 a $12 \mathrm{SM}$.

Durante esse estudo não foi observada uma atuação efetiva do INOCOOP no Subúrbio, construindo apenas um conjunto em parceria com a URBIS, cujo veremos mais adiante. A URBIS, empresa de economia mista, atuava atendendo a população de 3 a 5 SM no estado da Bahia, no mercado que Mendonça (1989) chamará de "popular".

Cabe dizer que a URBIS, legava a construção de seus empreendimentos para incorporadoras privadas, por isso era preciso incentivos estatais para tornar as construções rentáveis. Para isso, fazia-se necessário a concessão de subsídios estatais, como a liberação de terrenos públicos em áreas compatíveis com as condições econômicas do mercado consumidor.

Ao todo a URBIS realizou três empreendimentos no Subúrbio Ferroviário de Salvador, os quais foram responsáveis por realizar alterações significativas na paisagem verde da região. A construção desses conjuntos é iniciada em 1968 e se estende até o início da década de 1980, precisamente, o ano de 1983.

O conjunto habitacional Almirante Tamandaré (figura 03) foi o primeiro construído na região, teve as suas obras iniciadas no ano de 1968 e finalizadas no ano seguinte. Localizado nas proximidades da Av. Afrânio Peixoto no bairro de Paripe, possui área total de $114.025 \mathrm{~m}^{2}$. Ao todo foram construídas 389 residências em lotes que favoreciam a ampliação, com o objetivo de propiciar moradia para os trabalhadores da Base Naval de Salvador.

No que tange as áreas verdes destinadas a arborização, nota-se a maior concentração destes espaços nas bordas do conjunto habitacional. Acerca das características dessa vegetação, observa-se 
que estão bastante modificadas de suas condições naturais de floresta ombrófila densa, pelo fato de serem compostas em maior proporção por vegetação de porte médio e com pouca presença de árvores de grande porte.

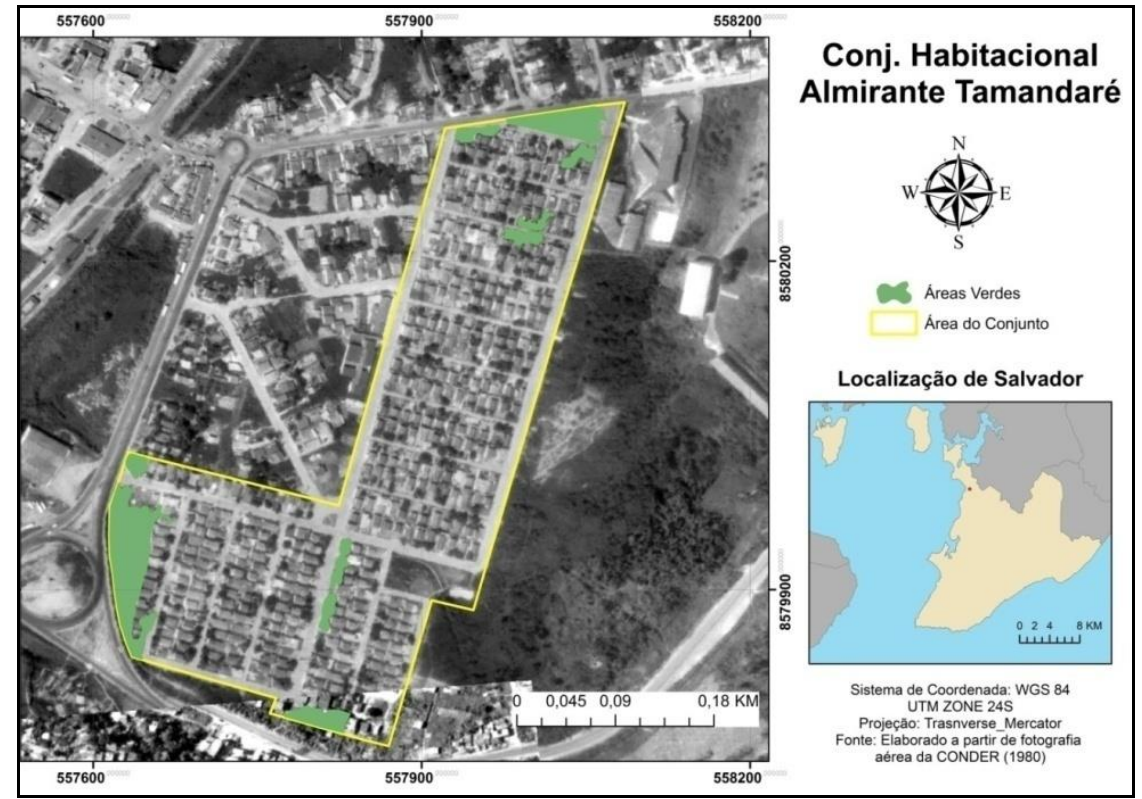

Figura 03: Área ocupada pelo conjunto Almirante Tamandaré Fonte: adaptado de fotografia aérea da CONDER (1989)

Ademais, vale dizer que a disponibilidade destes espaços verdes, principalmente nas bordas do conjunto (figura 03), é decorrente de duas questões constatadas nos trabalhos de campo. O primeiro corresponde ao relevo do terreno, que nestas partes vegetadas, apresentam condições muito íngremes que necessitaria de intervenções custosas para a construção de mais habitações, e que consequentemente aumentaria o custo das moradias, algo inviável devido às condições econômicas do público alvo.

Provavelmente, devido a isso, nos três projetos analisados, a URBIS não empregava o termo áreas verdes para designar todas as partes vegetadas presentes na poligonal do conjunto, e sim o termo áreas remanescentes. No caso do Almirante Tamandaré, estes espaços vieram a ser ocupados, futuramente, através de ocupações coletivas, prática comum em localidades onde as pressões por moradia são altas.

$\mathrm{O}$ outro fator que colaborou para a presença da paisagem verde no conjunto foram os espaços denominados conforme Falcão e Alecrim (2013) de "play lotes", espaços destinados nos projetos urbanísticos da URBIS para instalação de estruturas benéficas aos habitantes, a exemplo de praças. Porém, estes itens em alguns casos não vinham implantados de imediato com a entrega das residências, ficando a sua construção para depois, atitude que favorecia a ocupação da população da maioria destes espaços. 
Os trabalhos de campo, também possibilitaram observar a ausência de áreas verdes públicas que poderiam lhes fornecer alguns benefícios como a prática de atividades recreativas e, no ponto de vista físico, a facilitação da infiltração da água no solo e a amenização das médias de temperatura do ar.

Essa última informação se faz importante, pelo fato de o aumento da temperatura favorecer a proliferação de determinadas espécies de mosquitos da família dos Culicideos (vetores da dengue, febre amarela, filariose etc) (AMATO-LOURENÇO et al., 2016). Nessa mesma linha Afrane et al. (2005), nos indica que o aumento de $0,5^{\circ} \mathrm{C}$ na temperatura do ar favoreceu a reprodução do mosquito Anopheles, principal vetor de doenças perigosas como a malária e a filariose.

Assim, afora uma concentração maior de plantas em alguns terrenos privados, no Almirante Tamandaré, resta apenas algumas arvores isoladas plantadas pela população para fins paisagísticos, e que para Bargos e Matias (2010) não podem ser consideradas áreas verdes. Portanto, podemos inferir que pouco restou dos, aproximadamente, $8.976 \mathrm{~m}^{2}$ de vegetação remanescente deixada pela URBIS, a qual só na implantação do conjunto foi responsável pela supressão de cerca de 105.046 $\mathrm{m}^{2}$.

Com as obras iniciadas no ano de 1970 e finalizadas em 1972, o Dom Eugênio Sales (figura 04) corresponde ao segundo conjunto implantado pela URBIS no Subúrbio. Situado no bairro de Periperi, as margens da Rua Dr. Almeida, o complexo contém 286 casas e ocupa uma área de $55.203,90 \mathrm{~m}^{2}$, características que quando comparadas aos outros empreendimentos realizados na região, é possível considerá-lo como menos ambicioso idealizado pela companhia.

Para a sua construção, a empresa necessitou suprimir cerca de $50.776 \mathrm{~m}^{2}$ de áreas verdes do terreno, deixando, aproximadamente $4.427,9 \mathrm{~m}^{2}$ de áreas vegetadas distribuídas nas extremidades em alguns lotes disponíveis para a comercialização, os quais futuramente vieram a ser ocupados de forma legal ou informal, e em áreas remanescentes de tamanhos muito menores que as deixadas no Almirante Tamandaré.

A fotointerpretação possibilitou perceber que as áreas verdes do conjunto eram constituídas basicamente por vegetação de médio porte, refletindo as alterações das condições de floresta ombrófila densa. Assim, apenas no setor noroeste do conjunto, em um corredor estreito, é possível observar árvores de maior estatura (figura 04). 


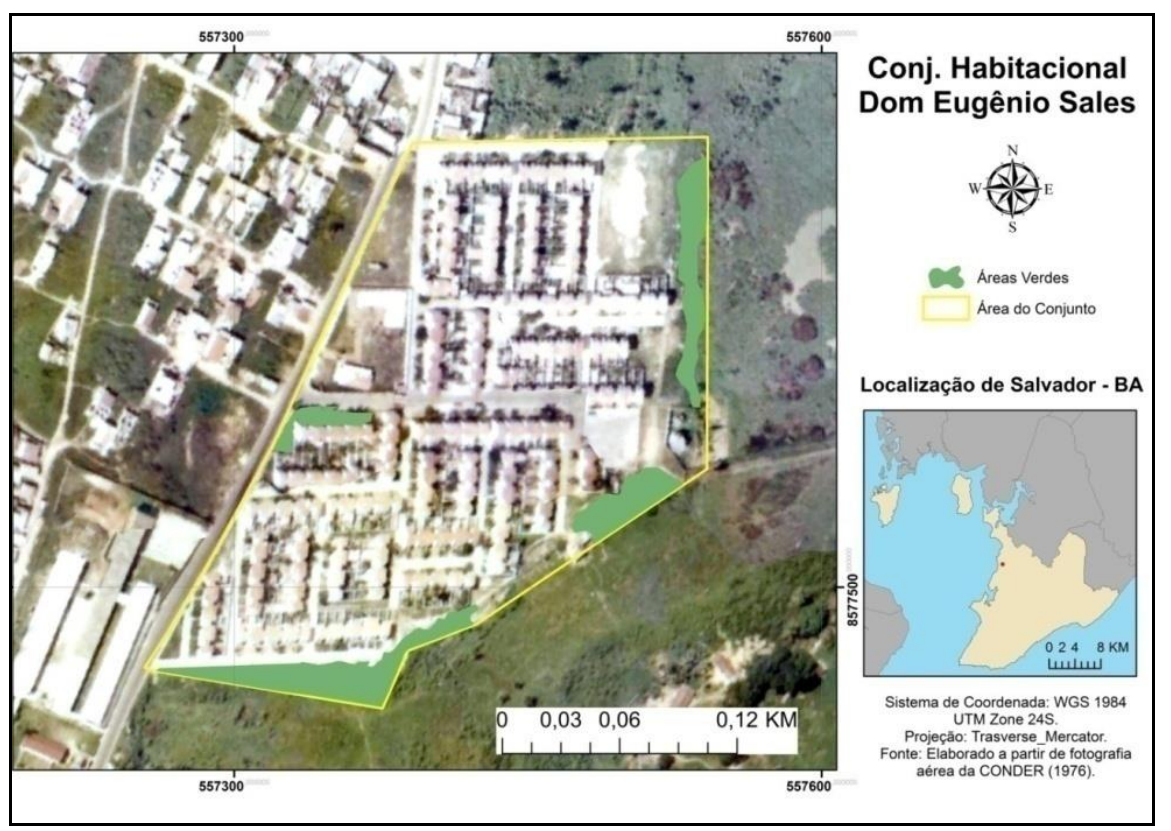

Figura 04: Área ocupada pelo conjunto habitacional Dom Eugênio Salles Fonte: adaptado de fotografia aérea da CONDER (1976)

Diferente do Almirante Tamandaré, as áreas verdes/espaços remanescentes do conjunto não estavam localizadas em áreas de difícil acesso ou de topografia que despendesse grandes investimentos para a preparação do terreno e assim receber a construção de mais residências (figura 04). Apesar dos motivos dessa postura adotada pela URBIS não serem claros, observou-se nos trabalhos de campo e em fotografia aéreas mais recentes a redução destes espaços, restando, em muitos casos, apenas uma árvore e o solo permeável.

Ademais, os plays lotes presentes neste conjunto não atendia os critérios expostos na metodologia deste trabalho para serem considerados uma área verde, por estes espaços estarem dotados apenas por gramíneas. Em relação às moradias, atualmente possuem aspectos bem diferentes do entregue em 1972, devido às ampliações realizadas por seus moradores a qual removeu as árvores (figura 04) presentes na frente ou no fundo dos lotes.

O último conjunto implantado na região foi construído em parceria com a INOCOOP, e recebeu o nome de Vista Alegre de Coutos. Localizado as margens da BA-528 no bairro de Coutos, seu registro em cartório data o ano de 1983. Ao todo foram construídas 276 casas e 91 edifícios de três andares, em uma área de $400.000 \mathrm{~m}^{2}$ sendo necessária para a sua implantação a supressão de, aproximadamente, $316.007 \mathrm{~m}^{2}$ de áreas verdes (figura 05).

Segundo Mendonça (1989) o grande número de construções verticalizadas visualizadas neste condomínio é corolário da postura mercadológica adotada pela URBIS a partir do ano de 1974, a qual consistia na construção de edifícios ao invés de residências com grandes lotes, pois 
desta maneira era possível construir o maior número de unidades habitacionais aproveitando melhor a área do terreno.

É importante dizer que, outrora, antes da construção do conjunto, a única estrutura presente no terreno, além da grande mancha verde bem concentrada em diversos trechos, sobretudo nas áreas mais elevadas, era uma estrada sem capeamento responsável por interligar o Subúrbio a BA-528. Hoje este caminho, corresponde a Rua Franco Velasco, a qual utiliza o mesmo traçado e realiza as mesmas funções.

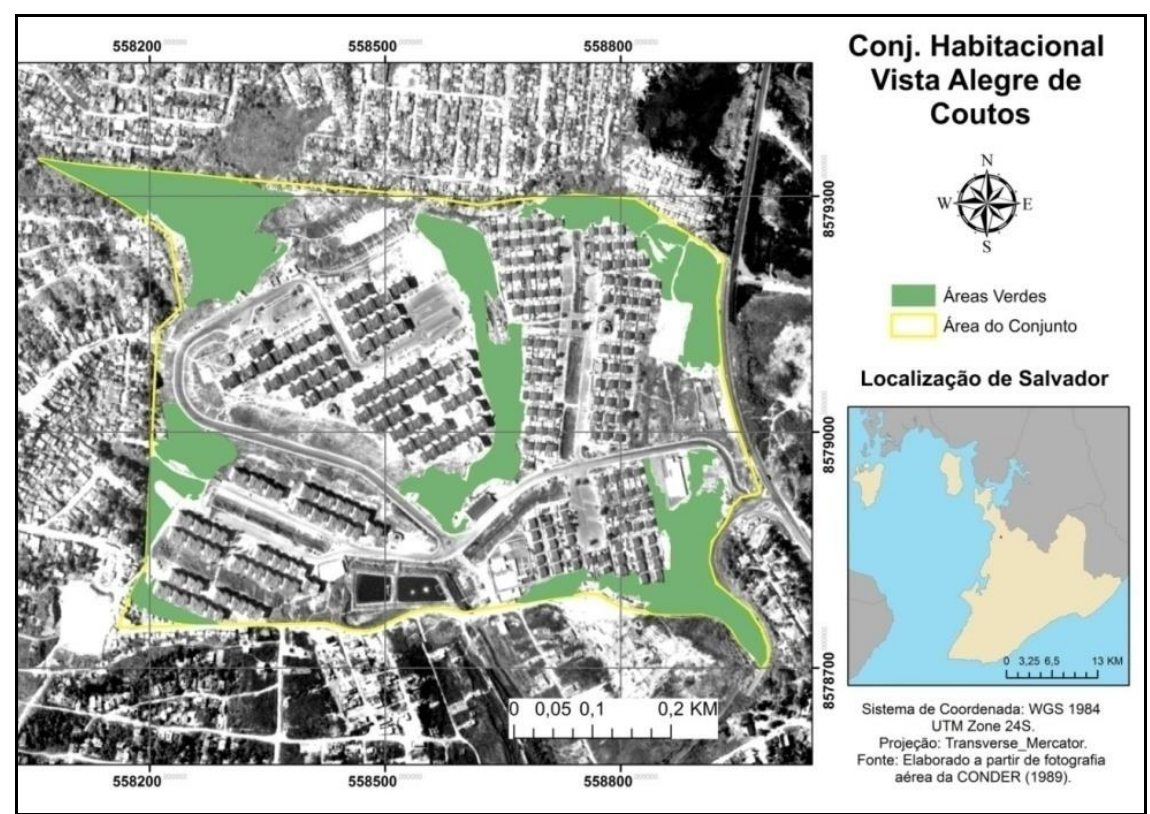

Figura 05: Área ocupada pelo conjunto habitacional Vista Alegre de Coutos Fonte: adaptado de fotografia aérea da CONDER (1989)

Analisando a figura 05, percebe-se a grande concentração de áreas verdes nas bordas do terreno e ao centro, condições não visualizadas nos outros empreendimentos implantados na região. Entretanto, a hipótese para a presença de tais espaços no conjunto, é que estes não foram utilizados para a construção de mais habitações, por necessitarem de intervenções custosas capazes de elevar os custos da obra. Assim, podemos dizer que dois motivos contribuíram para a manutenção das áreas verdes do conjunto: o relevo do terreno e a presença de pequenos cursos d'água.

O relevo do terreno por ser muito acidentado, com desníveis abruptos e encostas, favoreceu a preservação de boa parte destes espaços arborizados, os quais, ainda hoje, encontram-se cobertos pela vegetação. Estes desníveis estão concentrados a noroeste, sudeste e na parte central da figura 05; essa última parte corresponde à encosta responsável por dividir o conjunto em duas partes, denominada pelos moradores como "Vista de cima" e a parte de menor elevação de "Vista de baixo" (figura 06). 


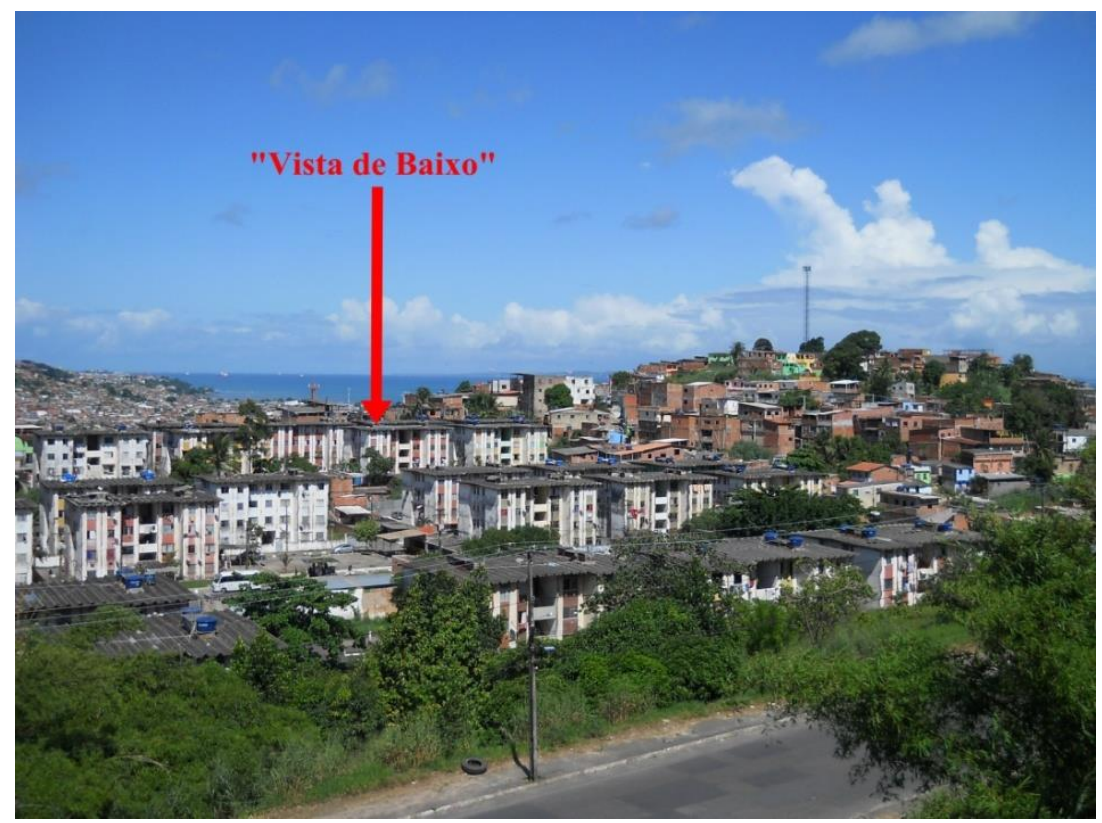

Figura 06: Destaque parte de menor elevação do conjunto Vista Alegre de Coutos. Fonte: Autores (2018)

Observando a figura 05, foi possível notar que além das áreas íngremes a presença de pequenos canais fluviais no setor noroeste do conjunto contribuiu para a manutenção de um grande espaço verde. Cabe colocar que, atualmente, estes riachos e as encostas continuam desempenhando papel importante, ao dificultar o avanço das ocupações informais, que se desenvolvem com velocidade na região, sobre as áreas verdes remanescentes do conjunto.

Sua preservação se faz importante, pois essas desempenham funções relevantes para os habitantes do conjunto, como: a estabilização das encostas amenizando os processos erosivos; diminuição das enchentes, uma vez que locais sem impermeabilização favorecem a infiltração da água no solo e reduzem a intensidade do escoamento superficial, o qual em condições insatisfatórias de limpeza urbana pode arrastar muitos resíduos, responsáveis por acumular água e favorecer a proliferação do Aedes aegypti, vetor da dengue.

No entanto, cabe pontuar que o término das obras do conjunto não deixou parte dos espaços verdes com as condições naturais apresentadas antes da sua implantação, pois muitos sofreram a redução de arvores de grande porte, deixando a vegetação em alguns trechos bastante espaçada ou rasteira, sobretudo nos locais mais planos próximos/entre os edifícios/residências.

Por fim, Mendonça (1989) explica que o baixo número de complexos habitacionais da URBIS no Subúrbio, se deu por uma série de fatores que dificultariam e encareceriam os processos construtivos: a composição geológica instável do solo massapé, e as necessidades de conter cursos d'água e de melhorar a infraestrutura precária da região.

Assim, a estratégia expansionista adotada pela URBIS para a implantação de seus conjuntos em regiões periféricas, com poucos serviços e afastadas das áreas mais valorizadas da cidade, Souza 
(2001) diz que essa atitude tomada pelo estado aumentou a segregação em Salvador, por ter impulsionado a divisão da cidade em duas partes, uma voltada para a classe mais abastada em setores da orla atlântica e outra voltada para os menos favorecidos em regiões como o Subúrbio e o Miolo.

Sobre a supressão de áreas verdes nas cidades, Marcarenhas e Cunha (2007), em seus estudos sobre a redução das áreas verdes em uma avenida da cidade de Salvador, apontaram que essa ocorre pelo fato dos equipamentos urbanos e dos investimentos imobiliários dotarem de maior prestígio que os espaços vegetados. Tal preferência ocorre por causa dos benefícios ambientais e paisagísticos serem colocados em segundo plano pelos planejadores do solo urbano.

\subsubsection{A atuação do Programa Minha Casa Minha Vida (PMCMV)}

O PCMV foi criado no ano de 2008, no segundo mandato do governo do Presidente Luiz Inácio Lula da Silva, com dois objetivos: o de promover habitação visando reduzir o déficit de moradias enfrentado pela população brasileira e, o outro, o de reforçar a atividade econômica frente à crise mundial através do incentivo ao setor da construção civil (MARQUES; RODRIGUES, 2013).

Ao todo, o programa já encerrou duas etapas, as quais foram iniciadas, respectivamente nos anos de 2009 e 2011. Atualmente, se encontra na sua terceira etapa, lançada no ano de 2016, ainda no governo da Presidente Dilma Roussef, com algumas alterações em relação às versões anteriores, no que tange ao aumento dos valores dos imóveis e do ajuste das faixas de renda. Acerca dessa última informação, podemos observar as mudanças conforme o quadro abaixo (quadro 01).

Quadro 01. Mudanças na faixa de atuação do PMCMV. Fonte: Elaborado pelos autores com base em informações de Matoso (2016)

\begin{tabular}{|c|c|c|}
\hline \multirow{2}{*}{ FAIXAS DO MCMV } & \multicolumn{2}{|c|}{ LIMITE DA RENDA } \\
\cline { 2 - 3 } & FASE 2 & FASE 3 \\
\hline Faixa 1 & $\mathrm{R} \$ 1.600$ & $\mathrm{R} \$ 1.800$ \\
\hline Faixa 1,5 & - & $\mathrm{R} \$ 2.350$ \\
\hline Faixa 2 & $\mathrm{R} \$ 3.275$ & $\mathrm{R} \$ 3.600$ \\
\hline Faixa 3 & $\mathrm{R} \$ 5.000$ & $\mathrm{R} \$ 6.500$ \\
\hline
\end{tabular}

Os destaques da terceira fase do PMCMV ficam por conta da inclusão da faixa 1,5, a qual pretende atuar entre as faixas 1 e 2 , atendendo às famílias com rendimentos de até $\mathrm{R} \$ 2.350$ mensais, aplicando juros de 5\% ao ano; e da ampliação do teto máximo das rendas familiares de todas as faixas para acessar os benefícios do programa. Ademais, é importante informar que as formas de adquirir as habitações são diferentes para os quatros seguimentos propostos pelo programa. 
Segundo Marques e Rodrigues (2013), a faixa 1 adquire o imóvel através de três maneiras: pelo Fundo de Arrendamento Residencial (FAR); e caso esteja concentrada em uma Entidade Organizadora (EO), por meio do Fundo de Desenvolvimento Social (FDS); e na realização de sorteios realizados pela prefeitura, a qual é responsável por cadastrar as famílias. Já as famílias das faixas 2 e 3, contam com as formas de financiamento da Caixa Econômica Federal (CEF), através dos recurso do Fundo de Garantia por Tempo de Serviço (FGTS).

Ainda segundo os mesmos autores, o PMCMV conta com diferentes formas de subsídio, os quais são aplicados de acordo com a faixa em que se enquadra o rendimento familiar. Assim, a faixa 1 recebe elevado subsídio; a faixa 2 recebe um valor moderado; e a três não conta com nenhum tipo de subsídio. Além disso, vale ressaltar que todas as faixas contam com o Fundo Garantidor da Habitação (FGHab), o qual viabiliza um sistema de compensação no caso de instabilidade de renda do comprador do imóvel.

No que tange à construção de habitações destinadas à faixa 1, através da metodologia aplicada, não foi possível encontrar nenhum conjunto no Subúrbio de Salvador, área conhecida pela sua carência em infraestrutura. Além disso, também não se fizeram presentes empreendimentos da faixa 2 e 3, os quais, provavelmente, estejam localizados em partes mais valorizadas do tecido urbano da cidade. No entanto, fizeram-se presentes três empreendimentos da nova faixa instituída pelo governo, a qual corresponde a 1,5 (quadro 02).

Conforme exposto no quadro 02, a TENDA foi a única empresa a atuar na produção habitacional planejada por meio do PMCMV, no Subúrbio de Salvador. Além disso, comparando a área total ocupada de seus conjuntos com os implantados pela URBIS, percebe-se que este primeiro realiza um melhor aproveitamento de seus terrenos, pelo fato de áreas relativamente menores comportarem um número muito elevado de moradias, devido à verticalização, reafirmando, também, uma nova tendência de uso de espaços menores com máximo de unidades habitacionais.

Quadro 02. Conjuntos Habitacionais do MCMV (Faixa 1,5) no Subúrbio Ferroviário. Fonte: Elaborado pelos autores com base em cálculos de áreas e informações do site da construtora TENDA (2018, a; b; c)

\begin{tabular}{|c|c|c|c|c|c|c|c|}
\hline \multirow{2}{*}{$\begin{array}{c}\text { Conjunto } \\
\text { Hab. }\end{array}$} & \multicolumn{2}{|c|}{ Construção } & \multirow{2}{*}{ Construtora } & $\begin{array}{c}\text { Área } \\
\text { Total }{\left(\mathbf{m}^{2}\right)}^{2}\end{array}$ & $\begin{array}{c}\text { Área } \\
\text { Verde } \\
\text { Reduzida } \\
\left(\mathbf{m}^{2}\right)\end{array}$ & \multicolumn{2}{c|}{ Habitações } \\
\cline { 2 - 6 } & Início & Fim & Apart. & $\begin{array}{c}\text { Tota } \\
\mathbf{l}\end{array}$ \\
\hline $\begin{array}{c}\text { Residencial } \\
\text { Bellas Águas } \\
\text { (Plataforma) }\end{array}$ & 2015 & 2017 & Tenda & $18.236,79$ & Não houve & 304 & 304 \\
\hline $\begin{array}{c}\text { Residencial } \\
\text { Mar Azul } \\
\text { (Plataforma) }\end{array}$ & 2016 & 2018 & Tenda & $89.759,50$ & $13.078,32$ & 600 & 600 \\
\hline
\end{tabular}




\begin{tabular}{|c|c|c|c|c|c|c|c|}
\hline $\begin{array}{c}\text { Residencial } \\
\text { Laguna 1 } \\
\text { (Rio Sena) }\end{array}$ & 2017 & $\begin{array}{c}\text { Em } \\
\text { Construção }\end{array}$ & Tenda & $6.574,41$ & Não houve & 160 & 160 \\
\hline
\end{tabular}

Acerca de suas produções habitacionais, observa-se uma atuação recente na área, sendo iniciada no ano de 2015, com o início das obras do Residencial Bellas Águas (figura 07a), finalizadas em 2017, localizado à margem da Rua Cabaceiras, no bairro de Plataforma, precisamente na latitude $-12,890517$ e longitude -38,475395, ocupando uma área total de 18.236,79 $\mathrm{m}^{2}$. Ao todo, foram construídas 19 torres, com apartamentos de 1 e 2 quartos, que quando somados totalizam 304 unidades habitacionais.

(a)

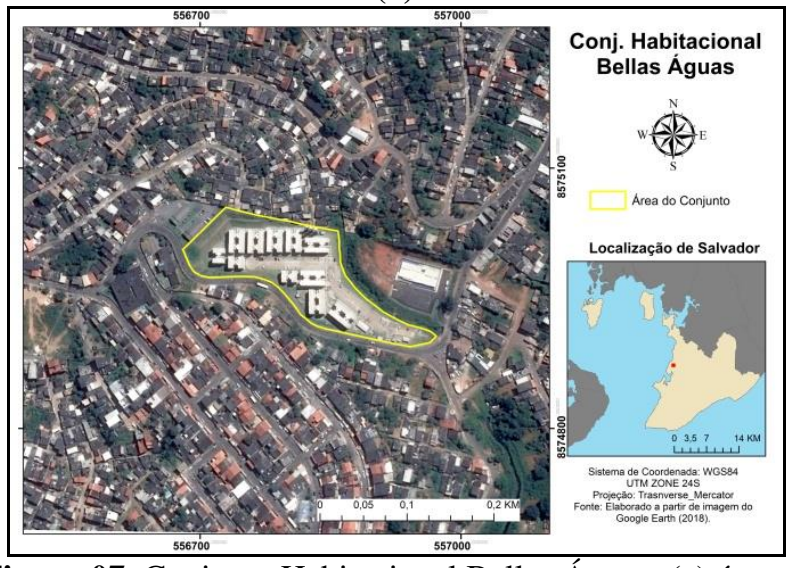

(b)

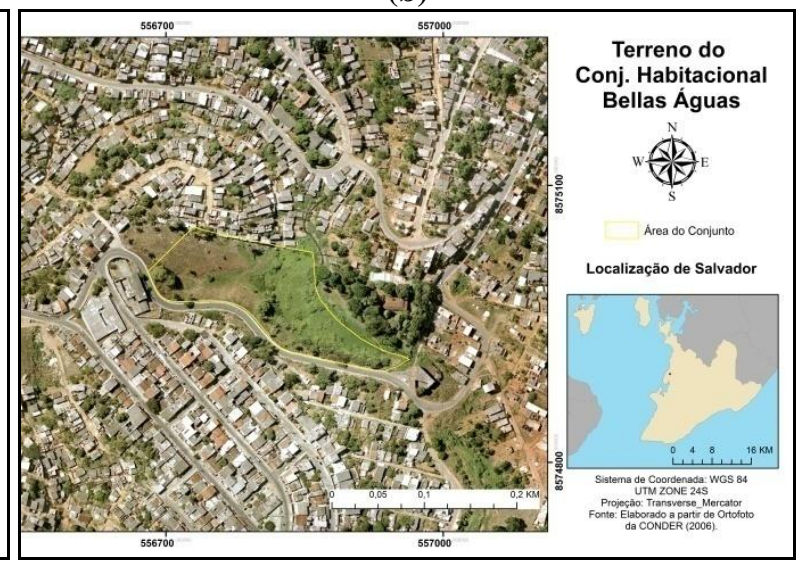

Figura 07. Conjunto Habitacional Bellas Águas: (a) área construída do conjunto habitacional (b) Terreno onde mais tarde veio a ser o conjunto habitacional Bellas Águas. Fonte: Elaborado pelos autores com base em imagem do Google Earth ${ }^{\circledR}$ (2018) e CONDER (2006)

De acordo com os critérios adotados neste trabalho para o que deve ser considerada uma área verde urbana, os quais correspondem ao conceito formulado por Bargos e Matias (2011), apurou-se que, o terreno ocupado pelo Bellas Águas, antes de sua construção, não deve ser classificado como tal. Isso ocorre pelo fato do espaço, apesar de não conter nenhum tipo de impermeabilização, a sua vegetação ser predominantemente rasteira, com a presença de algumas árvores de grande porte bem espaçadas (figura 07b). Diante das características apresentadas pela vegetação, o conceito melhor a ser aplicado corresponde ao de cobertura vegetal.

O segundo conjunto implantado está situado na Rua Formosa São João, no bairro de Plataforma, assim como o anterior, latitude -12,902397 e longitude -38.486661. Suas obras tiveram início no ano de 2016 e foram concluídas em 2018. Em relação à tipologia das unidades habitacionais, foram construídos apartamentos de 1 e 2 quartos, os quais totalizam 600 unidades, quantidade que coloca este empreendimento como o mais audacioso, quando levado em consideração o número de moradias, da construtora na região (figura 08a). 
(a)

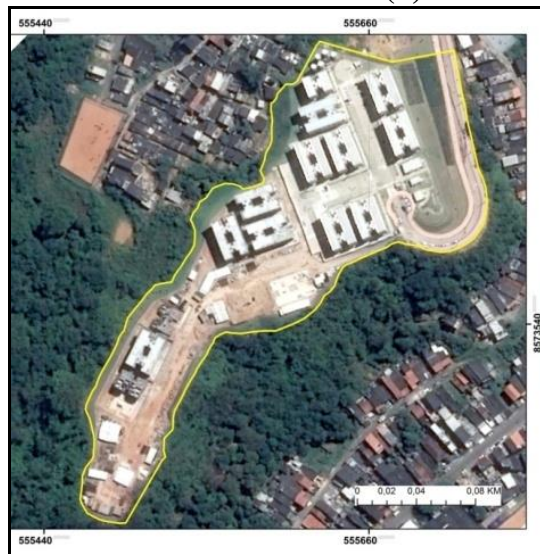

(b)

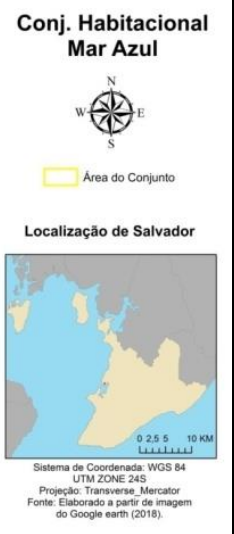

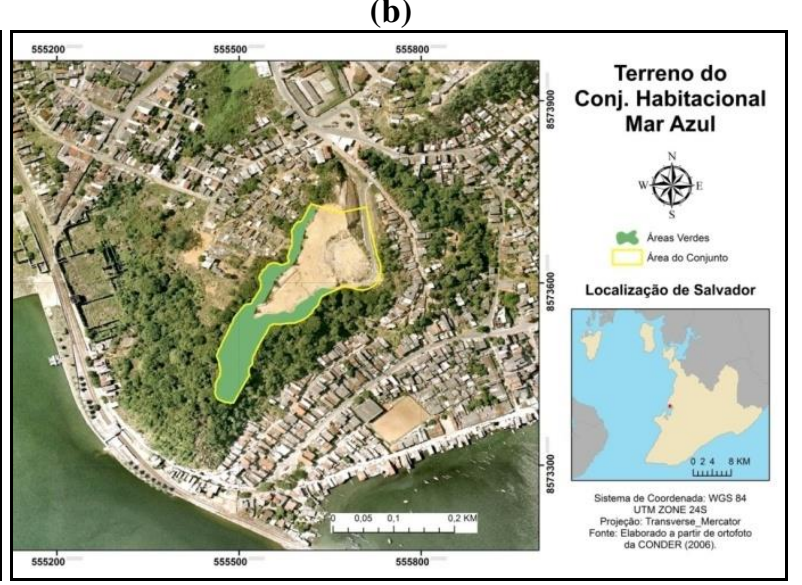

Figura 08. Conjunto Habitacional Mar Azul: (a) área construída do conjunto habitacional (b) Terreno onde mais tarde veio a ser o conjunto habitacional Mar Azul. Fonte: Elaborado pelos autores com base em imagem do Google Earth ${ }^{\circledR}$ (2018) e CONDER (2006)

Segundo as informações presentes no site da TENDA, a área total ocupada pelo empreendimento corresponde a 89.759,50 $\mathrm{m}^{2}$. Porém, conforme os cálculos de área efetuados no ArcGIS, constatou-se um valor bem inferior ao apontado anteriormente, de aproximadamente $33.057,207 \mathrm{~m}^{2}$. Uma suposição para essa inconformidade, é que o terreno adquirido pela construtora pode englobar a maior parte do morro, sobretudo a parte íngreme da encosta, a qual se encontra bastante arborizada e preservada (figura 08b).

Com base no mapa temático da figura 08b, o qual corresponde ao terreno onde, mais tarde, foi implantando o conjunto, podemos dizer que, ao todo, foi necessário suprimir, aproximadamente $13.078,32 \mathrm{~m}^{2}$ de área verde. Este valor se justifica pelo fato do terreno já apresentar uma boa parte sem nenhum tipo de cobertura vegetal, antes da implantação do empreendimento. Acerca das características da vegetação que era encontrada neste espaço, predomina a vegetação de porte arbóreo, do tipo ombrófila densa, com a presença de alguns caminhos sem impermeabilização, sobretudo na porção sudoeste do conjunto.

O memorial de incorporação do conjunto habitacional Laguna I (figura 09a) foi registrado em cartório no dia 12 de julho de 2017. Situado na Rua Pajussara, latitude -12,885661 e longitude 38,473037, no bairro do Rio Sena, o residencial encontra-se em construção e futuramente agregará 160 unidades habitacionais, de 1 e 2 dormitórios. Em relação ao tamanho do seu terreno, podemos considerá-lo como o menor já implantado pela construtora na região, pois se baseando nos cálculos efetuados pelo software ArcGIS, apresenta, aproximadamente, $6.574,41 \mathrm{~m}^{2}$ de área total. 
(a)

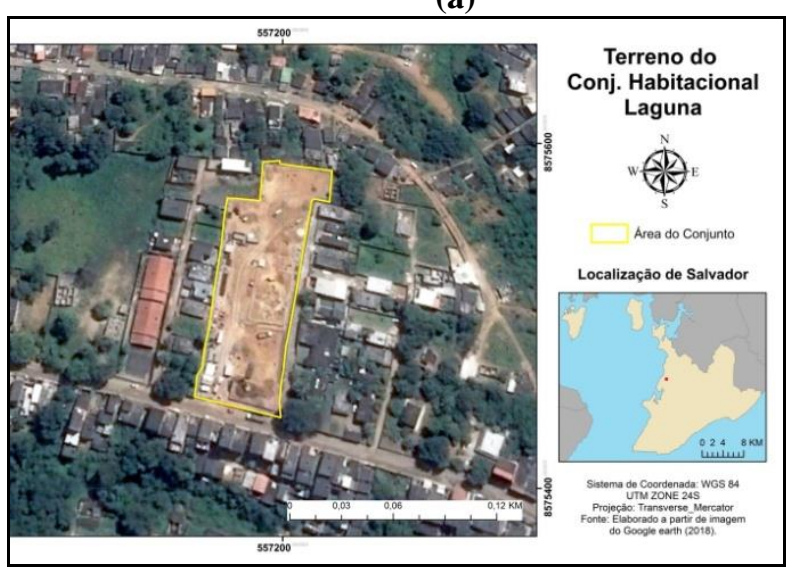

(b)

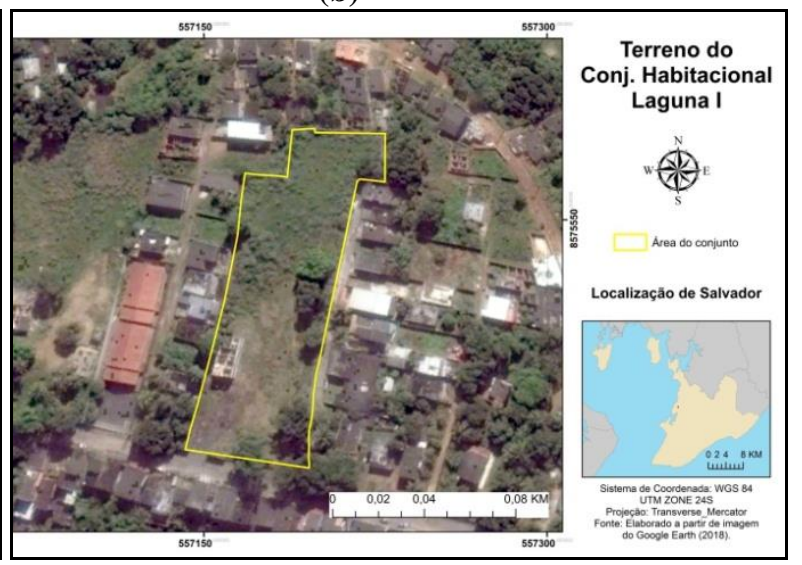

Figura 09. Conjunto Habitacional Laguna 1: (a) obras no conjunto habitacional (b) Terreno onde mais tarde veio a ter início as obras do conjunto habitacional. Fonte: Elaborado pelos autores com base em imagem do Google Earth® (2018)

Semelhante ao conjunto Bellas Águas, a área ocupada pelo Laguna I não se constituía um espaço verde, ao menos no período de obtenção da fotografia aérea (figura 09b), que corresponde ao início do ano de 2017. Apesar de conter algumas árvores de porte arbóreo e ausência de impermeabilização, nota-se o predomínio da vegetação rasteira na maior parte do sítio. Dessa forma, inferimos que o espaço já não era considerado uma área verde, mesmo antes da implantação do conjunto habitacional, podendo a sua supressão ter sido realizada pelo antigo proprietário do terreno.

Portanto, além da quantidade discreta de empreendimentos habitacionais implantados pelo PMCMV na área estudada, outras características chamam a atenção, como: o período recente de implantação destes; a faixa de renda para qual eles são destinados; a escolha dos terrenos. Sobre o início da construção habitacional em parceria com o PMCMV, nota-se um período relativamente recente, quando comparamos com a data de início do programa, refletindo um desinteresse das empresas em lançar empreendimentos para as faixas 1, 2 e 3, pois, é apenas com o advento da faixa 1,5 que se inicia a implantação dessas habitações planejadas.

No que tange aos terrenos escolhidos para a alocação desses empreendimentos, nota-se que a incorporadora foi cuidadosa em suas escolhas, pelo fato de todos estarem situados no bairro de Plataforma ou muito próximo a esse, o qual corresponde a um dos bairros com melhor urbanização e questões locacionais, por ser mais próximo das áreas centrais da cidade de Salvador, ao levarmos em consideração outros bairros do Subúrbio, com exceção de São João do Cabrito.

É importante colocar que a atuação da construtora na escolha da localização de seus empreendimentos é corolário da forma como foi pensado e vem sendo desenvolvido o programa habitacional, o qual, como já foi falado anteriormente, lega às empresas a escolha dos locais de implantação, elaboração do projeto e a faixa de renda destinada. 
Realizando uma comparação entre os empreendimentos da URBIS e os do PMCMV, percebe-se que as áreas verdes reduzidas para suas construções são bem inferiores, sendo de, aproximadamente, 13.078,32 $\mathrm{m}^{2}$. Esse dado é decorrência dos terrenos passarem por "limpezas" realizadas pelos antigos proprietários, as quais são responsáveis por desmatar e retirar muitas árvores com o objetivo de demonstrar que a área está sendo cuidada, evitando invasões coletivas. Por fim, a suposição é que estas terras eram utilizadas com fins especulativos, o qual foi atingido com a venda para a incorporadora responsável por construir os conjuntos habitacionais.

\section{CONSIDERAÇÕES FINAIS}

A partir dos métodos empregados foi possível perceber que a implantação de conjuntos habitacionais no Subúrbio vem contribuindo para a supressão de remanescentes de áreas verdes. A URBIS foi a maior atuante neste sentido, em razão do tamanho dos seus empreendimentos. Já o PMCMV, quando comparado à URBIS, a quantidade de áreas verdes reduzidas é bem menor, principalmente pelo melhor aproveitamento realizado por seus complexos e, principalmente, por causa da maioria dos locais onde foram implantados seus conjuntos não se constituírem espaços verdes.

Acerca da atuação da URBIS na região, percebe-se que a instalação de seus empreendimentos não visava a manutenção de espaços verdes para o cumprimento de processos básicos como a infiltração da água no solo e, muito menos, os ganhos paisagísticos propiciados por áreas arborizadas. Todavia, os empreendimentos apresentavam áreas contínuas e de uso comum mais amplas e com boa circulação, o que se difere bastante de outras cooperativas habitacionais que atuaram ao longo do tempo nesse tipo de produção de habitações.

Com esta situação, constata-se que, além da redução espacial de áreas verdes para a implantação de conjuntos, não ficou clara a preocupação com aspectos pertinentes ao conforto térmico e percentual dessas áreas voltados ao consumo humano, no sentido de promover um estado de bem estar ambiental e, por consequência, social. Com base nesta premissa, pode-se afirmar que este se tratou de um dos pontos de equívoco na urbanização promovida pela URBIS nessa área da cidade, cujo período permitiria ações interessantes.

Em relação aos conjuntos planejados no contexto do PMCMV, nota-se que estes, assim como o da URBIS colocam a questão ambiental em segundo plano. No entanto, a atividade desse programa habitacional no Subúrbio não vem provocando grandes impactos, pelo fato de estar sendo implantados em localidades onde a supressão já havia sido realizada por fins diversos.

Diante do exposto, o trabalho em tela permitiu a análise de questões relacionadas aos critérios de uso de áreas na produção do espaço urbano, tendo como foco a análise de sistemas 
habitacionais planejados construídos pelo Sistema Financeiro de Habitação. Daí então, a observação crítica no sentido de suscitar, futuramente, propostas de melhor adequação dos projetos ao espaço natural e às estruturas ambientais, no sentido de se fomentar um planejamento modernizado no que convém à expansão urbana.

\section{REFERÊNCIAS}

AFRANE, Y. A.; LAWSON, B. W.; GITHEKO, A. K.; YAN, G. Effects of microclimatic changes caused by land use and land cover on duration of gonotrophic cycles of Anopheles gambiae (Diptera: Culicidade) in Western Kenya Highlands. Journal of Medical Entomology, v. 42, Oxford: 2005.

AMATO-LOURENÇO, L. F.; MOREIRA, T. C. L.; FILHO, D. F. S.; MAUAD, T. Metrópoles, cobertura vegetal, áreas verdes e saúde. Estudos avançados. n.86, São Paulo: 2016.

BARGOS, D. C.; MATIAS, L. F. Áreas verdes urbanas: um estudo de revisão e proposta conceitual. Rev. da Sociedade Brasileira de Arborização Urbana, n. 3, Curitiba: 2011.

BRASIL. Ministério das Minas e Energia. Projeto RADAMBRASIL: levantamento dos recursos naturais. Folha SD. 24 Salvador. v. 24. Rio de Janeiro: Secretaria Geral, 1981, 624p.

Companhia de Desenvolvimento Urbano da Bahia. Fotografias Georreferenciadas: Salvador BA, 1976. Disponível em: 〈www.geopolis.ba.gov.br〉. Acesso em: 16/01/2017.

Companhia de Desenvolvimento Urbano da Bahia. Fotografias Georreferenciadas: Salvador BA, 1989. Disponível em: 〈www.geopolis.ba.gov.br〉. Acesso em: 16/01/2017.

Companhia de Desenvolvimento Urbano da Bahia. Fotografias Georreferenciadas: Salvador BA, 2006. Disponível em: <www.geopolis.ba.gov.br>. Acesso em: 16/01/2017.

COPQUE, A. C. S. M. ; SOUZA, F. A.; SANTOS, D. V. C.; PAIXÃO, C. P. Expansão urbana e redução de áreas verdes na localidade do Cabula VI Região do miolo da cidade do Salvador, Bahia. In: Simpósio Brasileiro de Sensoriamento Remoto - SBSR, 15, 2011, Curitiba. Anais eletrônicos... Curitiba: INPE, 2011. Disponível em:

<http://marte.sid.inpe.br/col/dpi.inpe.br/marte/2011/07.15.14.47/doc/p0313.pdf?metadatarepository $=\&$ mirror=urlib.net/www/2011/03.29.20.55 > . Acesso em: 25/01/2018.

FALCÃO, P. M; ALECRIM, G. M. Os recursos hídricos na evolução da habitabilidade do conjunto Feira I (Cidade Nova), Feira de Santana, Bahia. In Habitação e Meio Ambiente. 1 ed. Salvador: EDUNEB, 2013, 21-36 p.

INFORMS-CONDER. Companhia de Desenvolvimento Urbano do Estado da Bahia. Painel de Informações: dados socioeconômicos do município de Salvador por bairros e prefeiturasbairros. 5. ed. Salvador: CONDER, 2016. 189p.

MARQUES, E. C. L.; RODRIGUES, L. C. O Programa Minha Casa Minha Vida na metrópole paulistana: atendimento habitacional e padrões de segregação. R. B. de Estudos Urbanos e 
Regionais. n. 2. São Paulo: 2013. Disponível em:

<http://rbeur.anpur.org.br/rbeur/article/view/4740>. Acesso em: 16/10/2018.

MASCARENHAS, A. N.; CUNHA, R. D. A. Aplicação de SIG na análise da redução da paisagem verde na Av. São Rafael em Salvador-BA. Paisagem Ambiente: ensaios, n. 23. São Paulo: 2007. Disponível em: <http://www.revistas.usp.br/paam/article/view/87903 >. Acesso em: 04/07/2018.

MATOSO, F. Governo lança terceira fase do programa Minha Casa, Minha Vida. In G1, 2016. Disponível em: <http://g1.globo.com/politica/noticia/2016/03/governo-lanca-terceira-fase-doprograma-minha-casa-minha-vida.html>. Acesso em: 10/01/2018.

MENDONÇA, F. A. R. C. A Estratégia de Localização dos Conjuntos Habitacionais da URBIS em Salvador, entre 1964 e 1984. Revista de Urbanismo e Arquitetura. n. 1. Salvador: 1989. Disponível em: <https://portalseer.ufba.br/index.php/rua/article/view/3068>. Acesso em: 15/06/2018.

PORTO-GONÇALVES, C. W. A globalização da natureza e a natureza da globalização. 7 ed. Rio de Janeiro: Civilização Brasileira, 2006. 461 p.

SANTOS, E.; PINHO, J. A. G.; MORAES, L. R. S.; FISCHER, T. (Orgs.). O Caminho das Águas em Salvador: Bacias Hidrográficas, Bairros e Fontes. 1 ed. Salvador: CIAGS/UFBA, 2010.

SOUZA, A. G. Favelas, invasões e ocupações coletivas nas grandes cidades brasileiras(Re)Qualificando a questão para Salvador-BA. Cadernos Metrópole (PUCSP), v. 5, São Paulo: 2005. Disponível em: < https://revistas.pucsp.br/index.php/metropole/article/view/9297 >. Acesso em: 03/11/2017.

SEI, Superintendência de estudos econômicos e sociais da Bahia. Tipologia climática do estado da Bahia segundo Thornthwaite \& Matther, 1998. Disponível em:

<http://www.sei.ba.gov.br/site/geoambientais/cartogramas/pdf/carto_tip_clim.pdf>. Acesso em: 20/01/2018.

SEI, Superintendência de estudos econômicos e sociais da Bahia. Solos: Estado da Bahia, 2001. Disponível em:

<http://www.sei.ba.gov.br/images/inf_geoambientais/cartogramas/pdf/carto_solos.pdf $>$. Acesso em: 20/01/2018.

TENDA (a), Residencial Bellas Águas. Disponível em: <https://www.tenda.com/encontre-seuimovel/ba/salvador/residencial-bellas-aguas>. Acesso em: 25/01/2018.

TENDA (b), Residencial Laguna I. Disponível em: <https://www.tenda.com/encontre-seuimovel/ba/salvador/residencial-laguna>. Acesso em: 25/01/2018.

TENDA (c), Residencial Mar Azul. Disponível em: <https://www.tenda.com/encontre-seuimovel/ba/salvador/residencial-mar-azul >. Acesso em: 25/01/2018.

\section{AGRADECIMENTOS}

À Fundação de Amparo à Pesquisa do Estado da Bahia (FAPESB) pela concessão da bolsa de Iniciação Científica - PIBIC, ao Grupo de Pesquisa Terra\&Mar (IFBA/CNPq), Laboratório de 
Geografia Física (IFBA/Salvador). Projeto de pesquisa: Clima e Saúde: perspectivas geográficas no entorno da Baía de Todos os Santos, Bahia.

Recebido em: 27/08/2019

Aceito para publicação em: 01/11/2019 